\title{
Seroprevalence of Toxoplasma gondii Infection in Patients with Alzheimer's Disease
}

\author{
Mohammad Menati Rashno, ${ }^{1}$ Shirzad Fallahi, ${ }^{2,}{ }^{*}$ Farnaz Kheirandish, ${ }^{2}$ Shahrokh Bagheri, ${ }^{3}$ Mohammad \\ Hassan Kayedi, ${ }^{2}$ and Mehdi Birjandi ${ }^{4}$ \\ ${ }^{1}$ Department of Biotechnology, Damghan Branch, Islamic Azad University, Damghan, IR Iran \\ ${ }^{2}$ Department of Medical Parasitology and Mycology, School of Medicine, Lorestan University of Medical Sciences, Khorramabad, IR Iran \\ ${ }^{3}$ Razi Herbal Medicines Research Center, Lorestan University of Medical Sciences, Khorramabad, IR Iran \\ ${ }^{4}$ Department of Biostatistics, Lorestan University of Medical Sciences, Khorramabad, IR Iran \\ "Corresponding author: Shirzad Fallahi, Department of Medical Parasitology and Mycology, School of Medicine, Lorestan University of Medical Sciences, Khorramabad, IR Iran. \\ Tel: +98-6633120133, E-mail: Shfupdate@gmail.com, Falahi.Sh@lums.ac.ir
}

Received 2016 February 18; Revised 2016 June 10; Accepted 2016 June 12.

\begin{abstract}
Background: Toxoplasmosis is one of the most important diseases in humans and animals. Almost one-third of the human population around the world is infected with toxoplasmosis. The agent of this parasitic disease is a protozoan called Toxoplasma gondii ( $T$. gondii) that causes encephalitis in people with suppressed immune systems and abortion, mental retardation and chorioretinitis in the fetus. Alzheimer's disease (AD) is the most important neurodegenerative disease.

Objectives: Due to the high prevalence of toxoplasmosis in Iran and evidence on its impact on neurodegenerative diseases, this study was performed to evaluate the T. gondii infection in patients with AD.

Patients and Methods: In this case-control study, after selection of alzheimer's patients (APs) referred to Imam Reza psychiatric hospital of Khorramabad, west of Iran, and healthy controls (each group consisted of 87 individuals), using the convenience sampling method and under the supervision of a neurologist, blood samples were taken during July 2014 and January 2015. The collected samples were transferred to the research laboratory of parasitology under cold chain storage and then, the serum samples were separated by centrifugation and were frozen at $-20^{\circ} \mathrm{C}$ until use. The T. gondii IgM and IgG specific antibodies were assessed in serum samples using commercial Enzyme Linked Immunosorbent Assay (ELISA) kits.

Results: The overall prevalence of $T$. gondii infection in patients with AD and the control group, using ELISA assay, was obtained as $66.6 \%(58 / 87)$ and 56.32\% (49/87), respectively ( $\mathrm{P}=0.99)$. In this study, there was no significant association between T. gondii infection and AD. On the other hand, no statistically significant difference was observed between the two groups in terms of infection with $T$. gondii $(\mathrm{P}=0.99)$.

Conclusions: Higher prevalence of T. gondii in patients with AD compared to controls showed the possible impact of this parasite in $\mathrm{AD}$, which may exacerbate symptoms, and this requires special attention of specialists and patient families.
\end{abstract}

Keywords: Seroprevalence, Toxoplasma gondii, Patients with Alzheimer's Disease, Control Group

\section{Background}

Toxoplasmosis is a zoonotic disease caused by an obligate intracellular parasite, and routinely occurs through eating raw or undercooked infected meat, transfer of placental blood transfusion or organ transplant $(1,2)$. In most people with a healthy immune system, primary or chronic Toxoplasma gondii (T. gondii) infection has no clinical symptoms. Toxoplasmosis is particularly important in people with an impaired immune system, transplant patients and pregnant women $(3,4)$. Acquisition of infection occurs by eating raw/undercooked meat containing tissue cysts or food and water infected with oocysts excreted by a cat. Therefore, in areas where people eat more raw/undercooked meat or where cats are more closely in contact with humans, the rate of infection is higher (5).
Regularly, this parasitic infection is asymptomatic or has mild symptoms such as; eye problems and lymphadenopathy creates. The most common test for detection of $T$. gondii infection is the Enzyme-Linked Immunosorbent Assay (ELISA) technique, which is available as commercial kits. This technique detects parasite-specific IgM and IgG antibodies in human serum (6). Approximately one-third of the world's human population is infected with $T$. gondii. The released parasites go through different parts of the host body and enter all nucleated cells of the body, especially cells of the nervous system, which causes necrosis and creates massive lesions (7-10). Most immunocompetent individuals carrying the parasite cysts, especially in the central nervous system, have a model of chronic asymptomatic common infection $(11,12)$. There are several 
reports that show chronic Toxoplasma infection may alter human behavior. Behavioral changes attributed to infection due to T. gondii may be due to the parasite itself, which causes infection with nerve damage. IFN- $\gamma$, the main responsible cytokine for immunological defense against $T$. gondii is essential in all infected tissues, including the central nervous system (13-17). The biosynthesis of dopamine and/or serotonin could be directly affected by aromatic amino acid hydroxylases in T. gondii genome. Increase of dopamine in the brains of infected patients can be associated with the missing link between toxoplasmosis and mental disorders $(15,18)$. Although, latent cases treated as asymptomatic and clinically unimportant by medical professionals, results of animal studies and recent studies of personality profiles, behavior, and psychomotor performance have led to reconsider T. gondii infection as a risk factor for the development of some neuropsychiatric disorders, including schizophrenia, parkinson disease (PD) and alzheimer's disease (AD) $(10,13,18,19)$.

Alzheimer's disease is a progressive slow neurodegenerative disorder that is the most important and common cause of dementia in the elderly and is considered to normally occur at an older age. In this neurodegenerative disease, recent memory is severely damaged but the memory of past events, remains relatively healthy (20-22). The neurofibrillary filaments in brain cells, as well as the formation of amyloid plaques around nerve cells, are the main causes of $\mathrm{AD}$ (23). The clinical characteristics of AD include cognitive impairment forces, general decline in performance, disorder in the ability to perform daily living activities and behavioral disturbance (24). Injuries to the brain caused by plaque formation, including the release of the acetyl cholinesterase enzyme of plaques and toxic effects of amyloid deposits in brain cells, lead to the creation of inflammation in brain tissue. Neuro-filaments due to hyper-phosphorylation of Tau protein and the discontinuity of the skeletal structure of neurons that role phosphorylated state of Tau protein, maintaining the stability of microtubules constituent neural pathways $(25,26)$. Alzheimer's disease consists of three clinical stages including; mild, moderate and advanced. Early symptoms of AD gradual disruption memory, especially space memory that reduces the amount of acetylcholine as a result of the high release of the acetyl cholinesterase enzyme, which is the cause of Alzheimer's, impairs spatial memory (27). Some researchers have shown that the transport of oxygen to the brain and decrease in blood stream may act as a mechanism in the complex etiology of AD (28). This study was conducted with regards to the localization of T. gondii tissue cysts in the central nervous system and reports indicating the impact of $T$. gondii on neurodegenerative diseases $(7,9,10,13,16,29,30)$, as well as the lack of information about the prevalence of toxoplasmosis in patients with $\mathrm{AD}$ in studies conducted on the prevalence of parasitic infections in Lorestan province $(18,19,31-37)$.

\section{Objectives}

This study aimed to evaluate $T$. gondii infection in patients with AD.

\section{Patients and Methods}

\subsection{Study Population}

In this case-control study, the study population consisted of 87 alzheimer's patients (APs) and 87 healthy control subjects, who were selected using the convenience sampling method. To determine the sample size based on the statistical formula and with regards to $\mathrm{P}_{0}=0.35, \mathrm{P}_{1}=$ $0.55, \alpha=0.05$ and $\beta=0.20$, the sample size was calculated as 105 patients in each group. Because this number of intended patients was not found, the sample size was calculated to the maximum extent possible (87 people in each group).

The APs were under the medical supervision of a neurologist at the Imam Reza psychiatric hospital of Khorramabad, west of Iran. The mental status of APs was determined by a neurology specialist, using associated factors such as navigation, registration, attention, memory, language and construction (Table 1). According to these factors, the stage of AD was defined as mild, moderate and advanced. Only individuals, who were in one of the stages of $\mathrm{AD}$ were included in the case group. Based on the neurologist examination and documents, the control group had no neurological and psychological problem. People who had any items related to AD or were treated with any medication for neurodegenerative disorders were excluded from the control group. After describing the study and gaining the consent of participants, demographic variables such as age, gender, stage of $\mathrm{AD}$, type of food and drinking water, the level of education and place of residence were collected via a designed questionnaire. The study participants were recruited with a prior consent and they were assured that their names would not be mentioned and they would be notified about the results of the research. The ethics committees of the involved institutions approved this study (2014.3.1/200.22.45).

\subsection{Samples Collection}

Whole blood samples were taken from the APs and control group during July 2014 and January 2015. The collected samples were transferred to the research laboratory of parasitology along with ice and cold chain storage conditions, 
Table 1. Brief Examination of Mental Status of Alzheimer's Patients

\begin{tabular}{|c|c|}
\hline Factor Title & Score \\
\hline \multicolumn{2}{|l|}{ Navigation } \\
\hline $\begin{array}{l}\text { Time ( } 1 \text { score for each year, quarter, month, date and day of } \\
\text { the week) }\end{array}$ & 5 \\
\hline $\begin{array}{l}\text { Position (1 point for each State, country, city, buildings, units } \\
\text { or rooms }\end{array}$ & 5 \\
\hline \multicolumn{2}{|l|}{ Registration } \\
\hline Repeat the names of three devices (1 point for each device) & 3 \\
\hline \multicolumn{2}{|l|}{ Attention } \\
\hline $\begin{array}{l}7 \text { to } 7 \text { to subtract from } 100 \text { to } 5 \text { times or spell out the word } \\
\text { upside down }\end{array}$ & 5 \\
\hline \multicolumn{2}{|l|}{ Remind } \\
\hline $\begin{array}{l}\text { Repeat three devices that have already been named (1 point } \\
\text { for each device) }\end{array}$ & 3 \\
\hline \multicolumn{2}{|l|}{ Language } \\
\hline Naming pens or wristwatches (1 point each) & 2 \\
\hline Repeating a meaningless sentence & 1 \\
\hline Doing a three-step command (1 point for each) & 3 \\
\hline Reading and performing the sentence "close your eyes" & 1 \\
\hline Write a complete sentence & 1 \\
\hline \multicolumn{2}{|l|}{ Construction } \\
\hline Copy of the picture two intersecting pentagons & 1 \\
\hline Total & 30 \\
\hline
\end{tabular}

and then centrifuged for three to five minutes at $3500 \times \mathrm{g}$. The isolated serum was separately poured in sterile $1.5-\mathrm{mL}$ micro tubes and stored at $-20^{\circ} \mathrm{C}$ until use.

\subsection{Seroprevalence Evaluation}

To assess the anti-T. gondii IgG and IgM specific antibodies in serum samples, the Toxoplasma IgM and IgG ELISA kits (Pishtazteb Co, Iran) were used. Firstly, each serum sample was diluted by the diluent samples provided in the kit. Other experimental stages were performed according to the manufacturer's instructions. Optical density (OD) of each sample was measured using an ELISA reader (AWARENESS, Germany) and 450 and 630-nm filters. To determine the positive and negative samples for Toxoplasma specific antibodies, according to the kit instructions, a number of sample indexes were obtained by dividing the sample absorbance by the amount of cut-off. Based on this, amounts higher than 1.1 were considered as positive and lower than 0.9 were considered as negative. Samples with indexes between 0.9 and 1.1 were considered as suspicious and their fresh serum samples were tested again. To avoid any bias of equipment (ELISA reader, ELISA washer and samplers) and observer, all devices and instruments were calibrated before starting the procedures, and all experiments were done by one observer.

\subsection{Stage and Severity of $A D$}

In this study, the stage and severity of $\mathrm{AD}$ was determined according to Table 1 , which is the mini mental state examination of $\mathrm{AD}$ to check the possibility of dementia, and total accumulate points of less than 24 were considered as a landmark for $\mathrm{AD}$ (although this criterion changes partly with age and education level) (24).

\subsection{Statistical Analysis}

Results of the examined serum samples along with demographic information and other collected information via the questionnaires were analyzed using the SPSS 18 software (SPSS, Chicago, IL, USA). In this study, in addition to the multivariate logistic regression, Chi-square test and Fisher's exact test were used to analyze the data. Associations were tested using odds ratios (OR) and 95\% confidence intervals (CI) after adjustments. A P value of $<0.05$ was considered statistically significant for differences.

\section{Results}

\subsection{Demographic Characteristics and Seroprevalence Status of the Participants}

The average age of the subjects was $21.71 \pm 61.9$ years and in terms of gender, there were 66 males (37.9\%) and 108 females (62.1\%). The examined variables of participants in terms of infection with $\mathrm{AD}$ are shown in Table 2. The seroprevalence of $T$. gondii in patients with AD and the control group was 66.6\% (58/87) and 56.32\% (49/87), respectively. Various titers of the Toxoplasma-IgG antibody were found in 107 cases (61.5\%) of the total cases, which indicate the chronic phase of Toxoplasma infection. In none of the subjects the Toxoplasma-IgM antibody was found to have a relationship with the acute phase of the disease. In the present study, the chi-square test showed that there was a significant relationship between the seroprevalence of Toxoplasma and variables of age $(\mathrm{P}=0.016)$, gender $(\mathrm{P}$ $=0.036)$, place of residence $(P<0.001)$ and the type of $\operatorname{diet}(\mathrm{P}=0.010)$ in both case and control groups. Therefore, the prevalence of $T$. gondii infection in residents of the city (63.8\%), who had a mixed diet (92\%), were older than 60 years (56.9\%), females (62.1\%) and tap water consumers (92\%) was significantly higher than the other groups (Table 3). 


\begin{tabular}{|c|c|c|}
\hline \multirow[t]{2}{*}{ Variable } & \multicolumn{2}{|c|}{ Disease status } \\
\hline & Alzheimer Patients No. (\%) & Healthy Control No. (\%) \\
\hline \multicolumn{3}{|l|}{ Gender } \\
\hline Male & $40(46.0)$ & $26(29.9)$ \\
\hline Female & $47(54.0)$ & $61(70.1)$ \\
\hline \multicolumn{3}{|l|}{ Place of residence } \\
\hline City & $61(70.1)$ & $50(57.5)$ \\
\hline Village & $26(29.9)$ & $37(42.5)$ \\
\hline \multicolumn{3}{|l|}{ Type of consuming water } \\
\hline Piped & $75(86.2)$ & $85(97.7)$ \\
\hline Well & $12(13.8)$ & $2(2.3)$ \\
\hline \multicolumn{3}{|l|}{ Type of diet } \\
\hline Mostly vegetables & $0(0.0)$ & $0(0.0)$ \\
\hline Mostly protein & $2(2.3)$ & $12(13.8)$ \\
\hline A mixture of both & $85(97.7)$ & $75(86.2)$ \\
\hline \multicolumn{3}{|l|}{ Education } \\
\hline Illiterate & $85(97.7)$ & $9(10.35)$ \\
\hline Elementary & $2(2.3)$ & $37(42.53)$ \\
\hline Cycle & $0(0.0)$ & $12(13.8)$ \\
\hline Diploma & $0(0.0)$ & $17(19.55)$ \\
\hline Advanced diploma & $0(0.0)$ & $2(2.3)$ \\
\hline Bachelor & $0(0.0)$ & $10(11.5)$ \\
\hline Age $($ Mean $\pm S D)$ & $78.17 \pm 10.38$ & $45.63 \pm 17.45$ \\
\hline
\end{tabular}

\subsection{Stage and Severity of $A D$}

In terms of stage and severity of $\mathrm{AD}, 15$ (17.2\%), 11 (12.6\%) and 61 (70.1\%) patients were at the mild, middle and advanced stage of the disease, respectively. According to the chi-square test, there was no significant relationship between the seroprevalence of Toxoplasma and stage of $\mathrm{AD}(\mathrm{P}$ $=0.310$ ) (Table 3 ).

\section{Discussion}

Toxoplasmosis is a zoonotic parasitic disease that can be transmitted to humans through various routes such as, food, water or soil contaminated with oocysts, raw or undercooked meat containing tissue cyst, trans-placental transmission, blood transfusion and organ transplantation $(3,38)$. Various techniques including indirect immunofluorescence, chemiluminescence histology, isolation of parasite, ELISA and polymerase chain reaction (PCR) have been used for detection the disease $(1,39,40)$ studies have shown that the brain is one of the main localization sites of $T$. gondii that the parasite localized in this part as the tissue cyst form. Due to the immune system response, the membrane-enclosed parasites in the brain constitute the tissue cysts. Since the brain is the primary target organ after infection with T. gondii, various psychiatric and behavioral disorders, as well as mental illnesses, can be associated with toxoplasmosis $(2,31,41)$. So far, the central nervous system infections have been proposed as possible etiologic factors in the development of sporadic AD.18 In this study, the prevalence of Toxoplasma-specific IgG antibodies in the serum of APs was slightly higher than the controls ( $66.6 \%$ and $56.32 \%$, respectively). This finding is partially consistent with results reported by Kusbeci et al., 2011, in which $44.1 \%$ of APs and $24.3 \%$ of controls were positive for IgG antibodies against T. gondii (28). Results and analysis of the data based on Chi-square and multivariate logistic regression tests in serological assays are as follows: a) with assumption of constant non-experimental variables, the risk of $\mathrm{AD}$ for men is almost 3.2 times more than women; according to the $\mathrm{P}$ value of 0.036 , the meaningful relation- 
Table 3. Crosstab of Participants Based on Different Examined Variables and Infection With T. gondi

\begin{tabular}{|c|c|c|c|}
\hline \multirow[t]{2}{*}{ Variable } & \multicolumn{2}{|c|}{ Toxoplasma Serology Result } & \multirow[t]{2}{*}{ Pvalue } \\
\hline & Positive No. (\%) & Negative No. (\%) & \\
\hline Gender & & & 0.036 \\
\hline Male & $38(21.8)$ & $28(16.1)$ & \\
\hline Female & $69(39.7)$ & $39(22.4)$ & \\
\hline Place of residence & & & $<0.001$ \\
\hline City & $54(30.33)$ & $57(32.8)$ & \\
\hline Village & $53(29.77)$ & $10(5.61)$ & \\
\hline Type of consuming water & & & 0.422 \\
\hline Piped & $93(53.4)$ & $67(38.5)$ & \\
\hline Well & $14(8.0)$ & $0(0.0)$ & \\
\hline Type of diet & & & 0.010 \\
\hline Mostly vegetables & $0(0.0)$ & $0(0.0)$ & \\
\hline Mostly protein & $13(7.30)$ & $1(0.56)$ & \\
\hline A mixture of both & $94(52.80)$ & $66(37.07)$ & \\
\hline Education & & & 0.005 \\
\hline Illiterate & $30(17.2)$ & $64(36.8)$ & \\
\hline Elementary & $27(15.5)$ & $12(6.9)$ & \\
\hline Cycle & $6(3.4)$ & $6(3.4)$ & \\
\hline Diploma & $8(4.6)$ & $9(5.2)$ & \\
\hline Advanced diploma and bachelor & $2(1.1)$ & $10(5.7)$ & \\
\hline Age, $($ Mean \pm SD $)$ & $65 \pm 20.3$ & $56.92 \pm 23.1$ & 0.016 \\
\hline Stage of Alzheimer's disease (Case group) & & & 0.310 \\
\hline Primary & $8(9.2)$ & $7(8.0)$ & \\
\hline Average & $9(10.3)$ & $2(2.3)$ & \\
\hline Advanced & $41(47.1)$ & $20(23.0)$ & \\
\hline
\end{tabular}

ship that can be caused by more exposure of men with the agent of the disease; b) with the assumption of constant non-experimental variables, for each unit increase in age, the chance of developing AD increases by $19 \%$; according to the $\mathrm{P}<0.001$ this increase was significant. The increased prevalence of toxoplasmosis with aging may indicate the association of AD with toxoplasmosis (Table 4) (30). The specific treatment in children has a better prognosis than adults, while the mortality rate is lower and the duration of treatment is shorter; $\mathrm{c}$ ) In patients with $\mathrm{AD}$, the symptoms of incontinence $(\mathrm{P}=0.012)$ and change the mode $(\mathrm{P}=0.014)$ showed a significant relationship with the results of serology test that these symptoms as the risk factors involved in AD can also be related to the increased prevalence of $T$. gondii; $\mathrm{d})$ The type of nutrition $(\mathrm{P}=0.010)$ and place of residence $(\mathrm{P}<0.001)$ also had a significant relationship with the results of the serology test (Table 3 ).

According to the results of the serological assay, the Toxoplasma-specific IgM antibody was not found in any of the patients with $\mathrm{AD}$ and the control group. It seems that most APs were infected, before developing the AD. In the present study, there was no significant association between AD and toxoplasmosis $(\mathrm{P}=0.99)$, however, there was a statistically significant association between the variables of age, gender, place of residence, type of nutrition and infection with $T$. gondii in the case and control groups (Table 3). These variables can be considered as important risk factors for AD.

The higher prevalence of $T$. gondii infection in APs compared to controls also showed the possible impact of this parasite in an outbreak of $\mathrm{AD}$ and exacerbation of symptoms, which requires special attention of specialist medi- 
Table 4. Influence of Age, Gender, Type of Drinking Water and Serology Test Result on Alzheimer's Disease Using Multivariate Logistic Regression

\begin{tabular}{|c|c|c|c|}
\hline Variable & Odds Ratio(OR) & Confidence Interval (CI, $95 \%$ ) & Pvalue \\
\hline Age & 1.19 & $(1.12-1.25)$ & $<0.001$ \\
\hline \multicolumn{4}{|l|}{ Gender } \\
\hline Male & Reference & & - \\
\hline Female & 3.2 & $(1.07-9.49)$ & 0.036 \\
\hline \multicolumn{4}{|c|}{ Type of drinking water } \\
\hline Well & Reference & - & - \\
\hline Piping & 0.47 & $(0.07-2.97)$ & 0.422 \\
\hline \multicolumn{4}{|c|}{ Serology test result } \\
\hline Negative & Reference & - & - \\
\hline Positive & 0.99 & $(0.32-3.08)$ & 0.99 \\
\hline
\end{tabular}

cal doctors and patients entourage. The present study was the first survey in which the seroepidemiology of T. gondii infection was investigated in APs in Iran. One limitation of our study was the lack of use of molecular techniques such as PCR and comparison with the ELISA test. In the event, it was possible to achieve more accurate and more detailed results.

\section{Footnote}

Conflict of Interest: None of the authors had any conflict of interest concerning the financial, material, or methods used in this study.

\section{References}

1. Motoya JG, Kovacs JA, Remington JS. In: Toxosplasma gondii. Principle and practice of infections diseases. 6 ed. Gerald LM, Raphael D, John EB, editors. 2. USA: Elsevier Churchill Livingstone; 2005. pp. 3170-91.

2. Holliman RE, Johnson JD, Adams S, Pepper JR. Toxoplasmosis and heart transplantation. I Heart Lung Transplant. 1991;10(4):608-10. [PubMed: 1911807].

3. Coelho RA, Kobayashi M, Carvalho LJ. Prevalence of IgG antibodies specific to Toxoplasma gondii among blood donors in Recife, Northeast Brazil. Rev Inst Med Trop Sao Paulo. 2003;45(4):229-31. [PubMed: 14502353].

4. Jones JL, Ogunmodede F, Scheftel J, Kirkland E, Lopez A, Schulkin J, et al. Toxoplasmosis-related knowledge and practices among pregnant women in the United States. Infect Dis Obstet Gynecol. 2003;11(3):13945. doi: 10.1080/10647440300025512. [PubMed: 15022874].

5. Hill D, Dubey JP. Toxoplasma gondii: transmission, diagnosis and prevention. Clin Microbiol Infect. 2002;8(10):634-40. [PubMed:12390281].

6. Alvarado-Esquivel C, Torres-Castorena A, Liesenfeld O, Garcia-Lopez CR, Estrada-Martinez S, Sifuentes-Alvarez A, et al. Seroepidemiology of Toxoplasma gondii infection in pregnant women in rural Durango, Mexico. J Parasitol. 2009;95(2):271-4. doi: 10.1645/GE-1829.1. [PubMed: 18922040].

7. Carruthers VB, Suzuki Y. Effects of Toxoplasma gondii infection on the brain. Schizophr Bull. 2007;33(3):745-51. doi: 10.1093/schbul/sbm008. [PubMed: 17322557].
8. Montoya JG, Liesenfeld O. Toxoplasmosis. Lancet. 2004;363(9425):1965-76. doi: 10.1016/S0140-6736(04)16412-X [PubMed: 15194258].

9. Koseoglu E, Yazar S, Koc I. Is Toxoplasma gondii a causal agent in migraine?. Am J Med Sci. 2009;338(2):120-2. doi: 10.1097/MAJ.ob013e31819f8cac. [PubMed: 19564786].

10. Miman O, Mutlu EA, Ozcan O, Atambay M, Karlidag R, Unal S. Is there any role of Toxoplasma gondii in the etiology of obsessivecompulsive disorder?. Psychiatry Res. 2010;177(1-2):263-5. doi: 10.1016/j.psychres.2009.12.013. [PubMed: 20106536].

11. Torrey EF, Bartko JJ, Lun ZR, Yolken RH. Antibodies to Toxoplasma gondii in patients with schizophrenia: a meta-analysis. Schizophr Bull. 2007;33(3):729-36. doi: 10.1093/schbul/sbl050. [PubMed:17085743].

12. Yazar S, Arman F, Yalcin S, Demirtas F, Yaman O, Sahin I. Investigation of probable relationship between Toxoplasma gondii and cryptogenic epilepsy. Seizure. 2003;12(2):107-9. [PubMed: 12566234].

13. Henriquez SA, Brett R, Alexander J, Pratt J, Roberts CW. Neuropsychiatric disease and Toxoplasma gondii infection. Neuroimmunomodulation. 2009;16(2):122-33. doi: 10.1159/000180267. [PubMed: 19212132].

14. Tamer GS, Dundar D, Yalug I, Caliskan S, Yazar S, Aker A. The schizophrenia and Toxoplasma gondii connection: infectious, immune or both?. Adv Ther. 2008;25(7):703-9. doi: 10.1007/s12325-0080063-5. [PubMed: 18563312].

15. Hermes G, Ajioka JW, Kelly KA, Mui E, Roberts F, Kasza K, et al. Neurological and behavioral abnormalities, ventricular dilatation, altered cellular functions, inflammation, and neuronal injury in brains of mice due to common, persistent, parasitic infection. J Neuroinflammation. 2008;5:48. doi:10.1186/1742-2094-5-48. [PubMed: 18947414].

16. Rozenfeld C, Martinez R, Seabra S, Sant'anna C, Goncalves JG, Bozza $M$, et al. Toxoplasma gondii prevents neuron degeneration by interferon-gamma-activated microglia in a mechanism involving inhibition of inducible nitric oxide synthase and transforming growth factor-beta1 production by infected microglia. Am J Pathol. 2005;167(4):1021-31. [PubMed: 16192637].

17. Fallahi S, Mazar ZA, Ghasemian M, Haghighi A. Challenging loopmediated isothermal amplification (LAMP) technique for molecular detection of Toxoplasma gondii. Asian PacJTrop Med. 2015;8(5):366-72. doi: 10.1016/S1995-7645(14)60345-X. [PubMed: 26003595].

18. Kheirandish F, Sharafi AC, Kazemi B, Bandehpour M, Tarahi MJ, Khamesipour A. First molecular identification of leishmania species in a new endemic area of cutaneous leishmaniasis in lorestan, iran Asian Pac J Trop Med. 2013;6(9):713-7. doi: 10.1016/s1995-7645(13)60124- 
19. Badparva E, Nayebzadeh H, Barkhordari MH, Ezatpour B. Epidemiological study of strongyloides stercoralis with a comparative diagnostic approach, in lorestan, west of iran. Arch Clin Infect Dis. 2014;9(2).

20. Ho L, Sharma N, Blackman L, Festa E, Reddy G, Pasinetti GM. From proteomics to biomarker discovery in Alzheimer's disease. Brain Res Brain Res Rev. 2005;48(2):360-9. doi:10.1016/j.brainresrev.2004.12.025. [PubMed: 15850675].

21. Pregelj P. Involvement of cholesterol in the pathogenesis of Alzheimer's disease: role of statins. Psychiatr Danub. 2008;20(2):162-7. [PubMed: 18587285].

22. Goodman G, Limbird L, Hardman J. The pharmacological basis of therapeutics. 10. London: McGraw-Hill; 2001. pp. 560-2.

23. Resende R, Moreira PI, Proenca T, Deshpande A, Busciglio J, Pereira $\mathrm{C}$, et al. Brain oxidative stress in a triple-transgenic mouse model of Alzheimer disease. Free Radic Biol Med. 2008;44(12):2051-7. doi: 10.1016/j.freeradbiomed.2008.03.012. [PubMed: 18423383].

24. Geldmacher DS, Whitehouse PJ. Differential diagnosis of Alzheimer's disease. Neurology. 1997;48(5 Suppl 6):S2-9. [PubMed: 9153154].

25. Tanzi RE, Bertram L. Twenty years of the Alzheimer's disease amyloid hypothesis: a genetic perspective. Cell. 2005;120(4):545-55. doi: 10.1016/j.cell.2005.02.008. [PubMed: 15734686].

26. Vepsalainen S. A molecular genetic study and expression-based analysis of risk factors of Alzheimer's disease.Department of neurology series of reports. 2007;90:119.

27. Dinamarca MC, Arrazola M, Toledo E, Cerpa WF, Hancke J, Inestrosa NC. Release of acetylcholinesterase (AChE) from beta-amyloid plaques assemblies improves the spatial memory impairments in APP-transgenic mice. Chem Biol Interact. 2008;175(1-3):142-9. doi: 10.1016/j.cbi.2008.05.026. [PubMed: 18599028].

28. Chang CY, Liang HJ, Chow SY, Chen SM, Liu DZ. Hemorheological mechanisms in Alzheimer's disease. Microcirculation. 2007;14(6):62734. doi: 10.1080/10739680701411056. [PubMed: 17710633].

29. Fond G, Capdevielle D, Macgregor A, Attal J, Larue A, Brittner M, et al. [Toxoplasma gondii: a potential role in the genesis of psychiatric disorders]. Encephale. 2013;39(1):38-43. doi: 10.1016/j.encep.2012.06.014 [PubMed: 23095600].

30. Kusbeci OY, Miman O, Yaman M, Aktepe OC, Yazar S. Could Toxoplasma gondii have any role in Alzheimer disease?.AlzheimerDis Assoc Disord. 2011;25(1):1-3. doi: 10.1097/WAD.0b013e3181f73bc2. [PubMed: 20921875].

31. Badparva E, Kheirandish F, Ebrahimzade F. Prevalence of intestinal parasites in lorestan province, west of iran. Asian Pac J Trop Dis. 2014;4:728-32.

32. Kayedi MH, Lines JD, Haghdoost AA. Evaluation of the wash resis- tance of three types of manufactured insecticidal nets in comparison to conventionally treated nets. Acta Trop. 2009;111(2):192-6. doi: 10.1016/j.actatropica.2009.04.002. [PubMed:19442959].

33. Kheirandish F, Tarahi M, Haghighi A, Nazemalhosseini-Mojarad E, Kheirandish M. Prevalence of intestinal parasites in bakery workers in khorramabad, lorestan iran. Iran J Parasitol. 2011;6(4):76-83. [PubMed: 22347316].

34. Kheirandish F, Tarahi MJ, Ezatpour B. Prevalence of intestinal parasites among food handlers in Western Iran. Rev Inst Med Trop Sao Paulo. 2014;56(2):111-4. doi: 10.1590/S0036-46652014000200004. [PubMed: 24626411].

35. Kheirandish F, Kayedi MH, Ezatpour B, Anbari K, Karimi Rouzbahani HR, Chegeni Sharafi A, et al. Seroprevalence of Human Fasciolosis in Pirabad, Lorestan Province, Western Iran. Iran J Parasitol. 2016;11(1):249. [PubMed: 27095965].

36. Omrani VF, Fallahi S, Rostami A, Siyadatpanah A, Barzgarpour G, Mehravar S, et al. Prevalence of intestinal parasite infections and associated clinical symptoms among patients with end-stage renal disease undergoing hemodialysis. Infection. 2015;43(5):537-44. doi: 10.1007/s15010-015-0778-6. [PubMed: 25869822].

37. Fallahi S, Rostami A, Mohammadi M, Ebrahimzadeh F, Pournia Y. Practical parasitology courses and infection with intestinal parasites in students. J Infect Public Health. 2016 doi: 10.1016/j.jiph.2015.12.010. [PubMed: 26796769].

38. Fallahi S, Kazemi B, Seyyed tabaei SJ, Bandehpour M, Lasjerdi Z, Taghipour N, et al. Comparison of the RE and B1 gene for detection of Toxoplasma gondii infection in children with cancer. Parasitol Int. 2014;63(1):37-41. doi: 10.1016/j.parint.2013.08.005. [PubMed: 23993996].

39. Arab-Mazar Z, Fallahi S, Koochaki A, Haghighi A, Seyyed Tabaei SJ. Immunodiagnosis and molecular validation of Toxoplasma gondiirecombinant dense granular (GRA) 7 protein for the detection of toxoplasmosis in patients with cancer. Microbiol Res. 2016;183:53-9. doi: 10.1016/j.micres.2015.11.006. [PubMed: 26805618].

40. Fallahi S, Seyyed Tabaei SJ, Pournia Y, Zebardast N, Kazemi B. Comparison of loop-mediated isothermal amplification (LAMP) and nestedPCR assay targeting the RE and B1 gene for detection of Toxoplasma gondii in blood samples of children with leukaemia. Diagn Microbiol Infect Dis. 2014;79(3):347-54. doi: 10.1016/j.diagmicrobio.2014.02.014. [PubMed: 24792838].

41. Gajewski PD, Falkenstein M, Hengstler JG, Golka K. Toxoplasma gondii impairs memory in infected seniors. Brain Behav Immun. 2014;36:1939. doi: 10.1016/j.bbi.2013.11.019. [PubMed: 24321215]. 